\title{
Oligopaints: highly efficient, bioinformatically designed probes for fluorescence in situ hybridization
}

\author{
Brian J Beliveau ${ }^{1 *}$, Eric F Joyce ${ }^{1}$, Nicholas Apostolopoulosa', Feyza Yilmaza ${ }^{1,2}$, Chamith Y Fonseka ${ }^{1}$, Ruth B McCole ${ }^{1}$, \\ Yiming Chang ${ }^{1,3}$, Jin Billy Li ${ }^{1,4}$, Tharanga Niroshini Senaratne ${ }^{1}$, Benjamin R Williams ${ }^{1,5}$, Jean-Marie Rouillard ${ }^{6,7}$, \\ Chao-ting $\mathrm{Wu}^{1}$
}

From Epigenetics and Chromatin: Interactions and processes

Boston, MA, USA. 11-13 March 2013

Fluorescence in situ hybridization (FISH) is a powerful tool to study chromosome structure, positioning, and gene expression on a cell-by-cell basis. We have developed Oligopaints [1], a PCR-based method for generating highly efficient FISH probes from complex DNA libraries. Our method can visualize genomic regions ranging in size from tens of kilobases to megabases with the same basic protocol and gives researchers precise control over the location and patterning of each probe set. We have mined the reference genomes of $C$. elegans, D. melanogaster, A. thaliana, M. musculus, and humans for genomically unique 32-base sequences with thermodynamically desirable hybridization properties, and have made these sequences available on the Oligopaints website [http:// genetics.med.harvard.edu] along with a suite of scripts and documentation that will assist researchers with probe set design and allow our technology to be extended to any organism whose genome has been sequenced. Oligopaints robustly label chromosomes both in tissue culture cells and whole-mount tissue preparations and can be generated using standard molecular biology techniques and equipment at a price well below the cost of commercial FISH probes. The flexibility offered by our bioinformatic design platform has allowed us to perform complicated hybridizations, such as the simultaneous targeting of RNA and the genomic DNA flanking its site of transcription. Thus, we anticipate that Oligopaints will be a valuable tool for the study of nuclear architecture and the relationship between chromosome positioning and gene expression.

'Department of Genetics, Harvard Medical School, Boston, MA, 02115, USA Full list of author information is available at the end of the article

\section{Author details}

'Department of Genetics, Harvard Medical School, Boston, MA, 02115, USA.

2Department of Biology, Boston University, Boston, MA, 02215, USA.

${ }^{3}$ Department of Genetics, Washington University School of Medicine, St. Louis, MO 63110, USA. Department of Genetics, Stanford University, Stanford, CA, 94305, USA. ${ }^{5}$ Fred Hutchinson Cancer Research Center, Seattle, WA, 98109, USA. ${ }^{6}$ MYcroarray Ann Arbor, MI, 41805, USA. ${ }^{7}$ Department of Chemical Engineering, University of Michigan, Ann Arbor, Ml, 48109, USA.

Published: 18 March 2013

\section{Reference}

1. Beliveau BJ, Joyce EF, Apostolopoulos N, Yilmaz F, Fonseka CY, McCole RB, Chang Y, Li JB, Senaratne TN, Williams BR, Rouillard JM, Wu CT: Versatile design and synthesis platform for visualizing genomes with Oligopaint FISH probes. Proc Nat Acad Sci 2012, Epub 2012 Dec 11.

\section{doi:10.1186/1756-8935-6-S1-P5}

Cite this article as: Beliveau et al:: Oligopaints: highly efficient,

bioinformatically designed probes for fluorescence in situ hybridization. Epigenetics \& Chromatin 2013 6(Suppl 1):P5.

\section{Submit your next manuscript to BioMed Central and take full advantage of: \\ - Convenient online submission \\ - Thorough peer review \\ - No space constraints or color figure charges \\ - Immediate publication on acceptance \\ - Inclusion in PubMed, CAS, Scopus and Google Scholar \\ - Research which is freely available for redistribution \\ Submit your manuscript at www.biomedcentral.com/submit}

